\title{
Mahoma, las viejas y el Paraíso: de antiguo hadiz a cuentecillo en colecciones españolas del XIX
}

\author{
Mohammed, the Old Women and the Paradise: \\ From an Ancient Hadith to a Short Story in Spanish \\ Collections from the 19th Century
}

\author{
Desirée López Bernal \\ Universidad de Granada \\ desiree@ugr.es \\ ORCID iD: https://orcid.org/0000-0002-9756-9062
}

\section{RESUMEN}

Tras los Siglos de Oro, el interés hacia los cuentos jocosos o cuentecillos en la literatura española se reaviva con fuerza en el s. XIX. Se imprimen entonces numerosas colecciones de relatos breves concebidas con el único objeto de hacer reír. Los gustos de la época se ven fuertemente impregnados por el orientalismo y, en consecuencia, abundan en dichas colecciones los materiales de temática árabe-islámica. El presente artículo se propone desvelar la trayectoria de un antiguo hadiz de la tradición árabe-islámica hasta alcanzar la literatura española decimonónica convertido en cuento. Se partirá de las versiones encontradas en El libro de los cuentos de Rafael Boira y El mundo riendo de Roberto Robert para, a partir de ellas, exponer el desarrollo en su tradición de origen y analizar la posible vía de llegada hasta los literatos españoles de un relato muy difundido por la tradición escrita europea del s. XIX.

Palabras Clave: Abulfeda; vida de Mahoma; hadiz; Rafael Boira; Roberto Robert; literatura española; s. XIX; cuentos humorísticos.

\section{ABSTRACT}

After Golden Ages, the interest to the jocular story or «cuentecillos» in Spanish Literature rekindles during the 19th century. Numerous collections of short stories were designed with the only objective to make people laugh. During the Golden Ages the preference was the Orientalism and for that consequence in this Spanish collection appears many Arab-Islamic tools. This article aims to make known the long history of ancient hadith of the Arab-Islamic tradition to get known into the 19th century in Spanish Literature such as story. We choose two versions found in $E l$ libro de los cuentos of Rafael Boira and El mundo riendo of Roberto Robert on the one hand for explaining the development in their origin tradition. On the other hand, in theses texts for ana- 
lyzed the possible via of arriving at the Spaniard's writers of this tale widely used in European written tradition in the 19th century.

Key words: Abulfeda; Life of Mohammed; Hadith; Rafael Boira; Roberto Robert; Spanish literature; 19th century; Jocular tales.

\section{INTRODUCCIÓN}

La literatura española conserva todavía parcelas por explorar. Es lo que ocurre con el cuento cómico o humorístico en el s. XIX. No tanto con el de creación estrictamente literaria dentro de esta tendencia o con el que -aun tradicional o folclórico- fue deslizado hábilmente y reelaborado por escritores de la talla de Fernán Caballero entre sus composiciones ${ }^{1}$. Las colecciones decimonónicas de relatos breves humorísticos ${ }^{2}$-a medio camino entre el folclore y la literatura; entre la creación, la re-creación y también la traducción- han sido objeto de esporádicas incursiones ${ }^{3}$, que dejan un amplio campo -de alto valor folclórico, además- en el que adentrarse mediante múltiples aproximaciones. Una de ellas - cuya primera aportación pretende ser este trabajo- es el examen de los relatos de tema árabe y de aquellos otros que -de origen árabefueron recuperados por los intelectuales españoles del XIX que se dejaron llevar por la atracción exótica hacia otros mundos y culturas despertada por el orientalismo, tan en boga en Europa a lo largo de aquel siglo y que decaería a partir del final de su sexta década ${ }^{4}$.

Como bien es sabido, el s. XIX en España fue un momento literario especialmente prolífico en lo que al cuento se refiere. Soplaban nuevos vientos en

${ }^{1}$ En su caso, este tipo de cuentos fueron recogidos también en recopilaciones. Sobre la presencia de cuentos folclóricos en sus obras consúltese Amores 2001b y Chevalier 1978b, 49-66. De modo general, la influencia de los cuentos folclóricos en las obras de escritores españoles del XIX fue destacada por el propio Chevalier (1982, 325-333 y 1984, 204-206). Amores (1997), por su parte, reunió en un catálogo la nómina de cuentos folclóricos reelaborados por los literatos españoles decimonónicos.

${ }^{2}$ Se debe distinguir en este caso entre las recopilaciones de cuentos estrictamente populares (como los Cuentos y chascarrillos andaluces tomados de la boca del vulgo de Juan Valera), y aquellas otras -a las que me estoy refiriendo- que beben mayoritariamente de la tradición literaria que las precede (las obras de Rafael Boira y Roberto Robert que citaré, entre otras), pero que mantienen una fuerte connotación tradicional y popular.

${ }^{3}$ Cito los trabajos de Agúndez García a propósito de las fuentes de la ingente colección de Boira $(2004,2005,2006 a, 2006$ b y 2006c) y otro artículo en la misma dirección en colaboración con Fradejas Lebrero (2006). También Chevalier se hizo eco de versiones de cuentecillos recogidas en algunas de estas colecciones en sus estudios sobre el cuento tradicional y folclórico en las letras españolas.

${ }^{4}$ Se suele tomar como hito que marcó el ocaso del movimiento orientalista en Occidente la inauguración del Canal de Suez, el 10 de marzo de 1869 (Litvak 1985, 19). 
Europa para el género desde que a principios de siglo los hermanos Grimm inauguraran el camino de registrar por escrito el patrimonio oral de los pueblos en forma de narraciones. Despojado paulatinamente de los prejuicios que ponían en duda su valor literario, el cuento fue entonces masivamente apreciado por parte de los intelectuales y literatos españoles 5 . De su mano, el relato breve humorístico de carácter tradicional -equivalente a lo que Maxime Chevalier denominaba «cuentecillo» $(1978 \mathrm{a}, 41)$ y etiquetado en esta centuria, entre otras variadas denominaciones, también como «cuento» ${ }^{6}-$ alcanzó cotas de atención comparables con la eclosión que en esa dirección caracterizó a nuestros siglos áureos ${ }^{7}$. Sin embargo, la tradición oral ya no fue la protagonista en las colecciones literarias decimonónicas que los reunían, tejidas en su mayor parte a partir de la tradición escrita precedente y obras de autores contemporáneos.

Una de las principales implicaciones del término «cuentecillo»-según quedó establecido por Chevalier- es precisamente su carácter jocoso o humorístico. Así explicaba Juan Valera (1896, IX-X) hacia finales de siglo la inclinación hacia lo que él denominaba «cuentos cómicos, jocosos ó chuscos», que presentaba como una necesidad ante la atmósfera triste y pesimista que envolvía su época ${ }^{8}$ :

Grande es la estimación que siempre y en todas partes se ha concedido á la literatura humorística. Hoy, que vivimos en una época triste, en una sociedad revuelta y algo desquiciada y con los espíritus llenos de melancolía á causa, en gran parte, del alimento malsano que nos propinan los pensadores y filósofos pesimistas, lo jovial y alegre es más de desear que nunca para remedio de aquel mal, para triaca de aquel veneno y para clara demostración de que el vulgo no está, por dicha, tan aburrido y desesperado como se supone, y aún se deleita en inventar ó guardar en la memoria y en referir cosas de burlas y de risa.

La lista de recopilaciones de cuentecillos llamados a despertar la risa en los lectores que ven la luz en España a lo largo del s. XIX - especialmente mediada dicha centuria- es considerable. No me refiero a las que -como la de Juan

${ }^{5}$ Baquero Goyanes $(1949,68-69)$ llamaba la atención sobre las reticencias de los literatos decimonónicos a hacer uso del término «cuento». Su uso generalizado tuvo lugar a partir de las últimas décadas del siglo, de la mano de los escritores naturistas.

${ }^{6}$ Sobre la evolución del término a lo largo del s. XIX cfr. Baquero Goyanes 1949, 5973 y Gutiérrez Díaz-Bernardo 2003, 18-20.

7 Dicha peculiaridad fue estudiada con detalle y destacada en sus trabajos por el mencionado hispanista y folclorista. Consúltese, por ejemplo, Chevalier 1978a, 60ss. Otra tendencia ampliamente cultivada en la España decimonónica en relación con el humor fue la satírica, especialmente centrada en la política y que, como el cuento y el cuentecillo, encontró una aliada perfecta en la prensa.

${ }^{8}$ Estos cuentos configuran la tercera de las clases de cuentos populares que distinguía, junto con los cuentos de hadas o de encantamientos y los hechos, lances, anécdotas o dichos conservados por la tradición (Valera 1896, VII-IX). 
Valera o las reunidas por Antonio Machado Álvarez y su nutrido grupo de colaboradores- se adentran de lleno en el ámbito del folclore y del cuento oral.

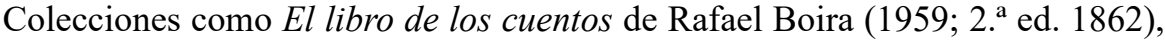
el Museo cómico (1863-1864) de Manuel del Palacio y Luis Rivera (ambos editores del periódico satírico Gil Blas) o El mundo riendo (1866) de Roberto Robert, imitan las apreciadas florestas de siglos anteriores. Son el resultado de un esfuerzo erudito de recopilación de materiales, lo mismo de repertorios españoles, que extranjeros, y también -aunque en menor medida- de la tradición oral ${ }^{9}$. A unos y a otra recurren en busca de anécdotas, chistes, chascarrillos, en fin, de todo aquello que pudiera dibujar una sonrisa en sus lectores. Veamos qué ocurre con el cuentecillo que protagoniza esta investigación.

\section{LAS VERSIONES DECIMONÓNICAS DE BOIRA Y ROBERT}

Abrimos en primer lugar las páginas del voluminoso libro de cuentos de Rafael Boira, concebido con el único fin de divertir: «Riamos á carcajadas; esta es nuestra bandera» escribía su autor en su explícito prólogo (1862, I: 6). Publicado en tres tomos, predominan los relatos en prosa, dispuestos todos ellos sin atender a ningún criterio concreto. El cuentecillo que nos interesa se lee en el volumen primero y lleva por título «El paraíso de los moros»:

Cuenta Abulfeda que una vieja preguntaba á Mahoma lo que necesitaba hacer para ganar el Paraiso. El falso profeta respondió:

-Amiga mía, el Paraiso no se ha hecho para las viejas.

Oyendo esto la del cuento, principió á llorar con la mayor ansiedad; pero Mahoma la consoló diciendo:

-Tranquilízate, no entran las viejas al Paraiso, pero es porque rejuvenecen todas al llegar a la puerta y se quedan de quince años.

-¡Loado sea Dios y su profeta! Esclamó la vieja retirándose (Boira 1862, I: 94).

Como es habitual en él, Rafael Boira no precisa la procedencia de los materiales que ha reunido, aunque -como muestran, en parte, los trabajos de José Luis Agúndez García (2004, 2005, 2006a, 2006b y 2006c) y de Fradejas Lebrero y Agúndez (2006)- el grueso de ellos los rescata de la tradición literaria anterior. Él mismo lo dejaba claro en el subtítulo que dio a su colección, que describía como «Recapitulación de todas las florestas, de todos los libros de cuentos españoles, y de una gran parte de los extranjeros».

Producto también del próspero renacer que a lo largo del siglo XIX experimentaron los cuentecillos, El mundo riendo del periodista, editor e intelectual liberal Roberto Robert -natural de Barcelona- saldría a la luz cuatro años después

${ }^{9}$ Esto último no quita que se descubra en ellos numerosos cuentos de carácter folclórico o que fueron tradicionales en centurias anteriores. 
que la segunda edición de la colección de Rafael Boira. Al igual que la del valenciano, la obra de Roberto Robert -menos extensa- reunía en un solo volumen variados materiales destinados a hacer reír, cuyo título le bastó para declarar sus intenciones. El cuentecillo que reproducíamos en párrafos anteriores es uno de los más de ciento sesenta que José Agúndez García (2005, 64, n. ${ }^{\circ} 352$ ) señalaba en uno de sus trabajos entre los coincidentes en las obras de ambos autores ${ }^{10}$. Sin apenas variaciones en su texto, Robert recogía el siguiente relato:

Refiere Abulfeda que una vieja fué á preguntar á Mahoma lo que debía hacer para alcanzar el Paraiso.

-El Paraiso no se hizo para las viejas, respondió el profeta.

La vieja echó á llorar amargamente y Mahoma añadió:

-Consuélate, que si no hay viejas en el Paraiso, es porque toda mujer se rejuvenece antes de entrar en él.

-¡Alabanza á Dios y á su profeta! -gritó la vieja, y corrió contentísima sin querer más (Robert 1866, 457).

Se observa cómo se mantiene incluso la referencia al que parece ser su transmisor, un personaje árabe cuyo nombre fue castellanizado como Abulfeda, del que más adelante hablaré. Por lo demás, se aprecian leves modificaciones respecto al cuentecillo que reproducía Rafael Boira, que no afectan lo más mínimo a su reducida línea argumental, igual en ambas versiones. Estas similitudes dan pie a pensar que una y otra podrían estar relacionadas y que $E l$ libro de los cuentos de Rafael Boira habría proporcionado el relato a Roberto Robert, aunque este no lo indique.

En este sentido, el barcelonés se muestra bastante metódico a lo largo de su colección a la hora de señalar las fuentes de los materiales que reunió. Lo mismo encontramos textos rescatados de obras de autores españoles de siglos pasados (entre ellos clásicos, como Lope de Vega, Luis de Góngora o Tirso de Molina), que también de otros contemporáneos a él (Juan Eugenio Hartzenbusch, Manuel del Palacio o Pedro Yago). Idéntica situación se da entre los escritores extranjeros en cuyas obras bucea, tanto de épocas anteriores (Tallemant des Réaux), como decimonónicos (Alfonso Karr) ${ }^{11}$. Sin embargo, esta no es regla que siga en todos los casos, y relatos que en apariencia pudieran resultar recogidos de la tradición oral por él, resultan haber sido entresacados de obras literarias precedentes. Sirva como ejemplo el cuentecillo que sigue, tomado de El remedio de la melancolía de Agustín Pérez Zaragoza Godínez (1821, III: 112), publicada en 1821 y que su autor presentaba como «colección de recreaciones jocosas e instructivas»:

${ }^{10}$ De los 167 cuentos compartidos entre Rafael Boira y Roberto Robert, 13 lo son también con la Floresta española de Melchor de Santa Cruz.

${ }^{11}$ Sobre sus fuentes, el propio Roberto Robert refleja lo señalado en el subtítulo a su obra: Colección enorme, selecta, novísima en prosa y verso sacada de autores antiguos y modernos, nacionales y extranjeros, clérigos y seglares, famosos y oscuros. 
Un pobre tintorero, impregnadas las manos de campeche, tuvo que prestar juramento en un tribunal, y apenas levantó la mano, le dijo el juez:

-Quítese V. los guantes.

-Póngase V. los anteojos, le replicó el otro con viveza (Robert 1866, 373).

Volviendo al relato que nos ocupa, el silencio que guarda Roberto Robert en relación con su fuente no tiene por qué ser necesariamente un indicador de su procedencia oral. Me parece que - de hecho- no lo es. Lo que no estamos en condiciones es de afirmar si el barcelonés se inspiró en el texto de Rafael Boira y a partir de él lo reelaboró, o si uno y otro bebieron de una misma fuente escrita que -como expondré-, fue casi con toda probabilidad francesa. Un estudio contrastado de los cuentos coincidentes en Rafael Boira y Roberto Robert sacados a la luz por José Luis Agúndez García descubriría cómo no siempre las versiones que cada uno recogió de un mismo relato se hallan próximas, mientras que en otras más cercanas se producen variaciones en su texto, quién sabe si por obra del propio Robert sobre el de Boira o a partir de otra fuente que no precisó. Lo que parece seguro es que los cuentos de Boira no fueron siempre su fuente directa.

Las versiones literarias que de nuestro cuentecillo circularon por escrito en la España del XIX se completan con su eco en la boyante prensa española del posromanticismo. El periodo literario decimonónico no se puede -de hechoentender sin la prensa, convertida en un verdadero apéndice de las obras literarias y en un efectivo escaparate proyectado hacia el público lector, al que muchas de aquellas se asoman por entregas ${ }^{12}$. El número de periódicos que se imprimen en España a lo largo de la centuria decimonónica se multiplica exponencialmente y el cuento - de creación literaria o de aire más popular- encuentra en ellos un excelente medio de difusión ${ }^{13}$. Así le ocurre al cuentecillo. No falta en los diarios una sección reservada al entretenimiento de sus lectores con este tipo de relatos. Nacen, además, multitud de revistas satíricas y de contenido festivo, que dibujan un rico panorama del género humorístico y evidencian el gusto de la época hacia él.

Retomando el cuentecillo objeto de estudio, las páginas del madrileño diario El Imparcial del 1 de abril de 1868 lo acogían en su «sección amena», en una versión sin duda extraída de la obra de Roberto Robert:

Refiere Abulfeda que una vieja fué á preguntar á Mahoma lo que debía hacer para alcanzar el Paraiso.

\footnotetext{
12 Acerca del papel desempeñado por la prensa en la difusión del cuento español en general, y más concretamente del literario, cfr. Baquero Goyanes 1949, 158-171 y Palomo $1997,152-159$ y $253-267$.

${ }_{13}$ Un ejemplo es la primera colección de cuentos folclóricos española, reunida por Juan de Ariza y que vio la luz por entregas entre los años 1848-1850 en el Semanario Pintoresco Español, tal y como señalaba Amores (2001a, 25).
} 
-El Paraiso no se hizo para las viejas, respondió el profeta.

La vieja se echó á llorar amargamente y Mahoma añadió:

-Consuélate, que si no hay viejas en el Paraiso, es porque todas se rejuvenecen antes de entrar en él.

-¡Alabado sea Dios y su profeta! -gritó la vieja contentísima, sin querer más ( $E l$ Imparcial 1868,3$)^{14}$.

El relato adquiría así por primera vez vida y difusión autónoma, al dar el salto de la colección del barcelonés a un periódico, donde se publica de forma independiente ${ }^{15}$.

Casi dos décadas después, volvía a estar de plena actualidad en los periódicos españoles y de lengua hispana de América. Hacía treinta años exactos de la publicación de la colección de Roberto Robert, que parecía seguir estando vigente. De ella, o bien del periódico El Imparcial, se extrajo para su impresión en el número del 19 de marzo de 1896 del semanal El Regidor de San Antonio de Texas $(1896,2)^{16}$. Su texto es un calco de los dos mencionados.

Ligeramente reelaborado, el cuentecillo aparecía en la sección «de todas partes» del número correspondiente al 27 de noviembre de 1896 del también madrileño El Correo Español. Diario tradicionalista, bajo el rótulo «la anécdota diaria»:

Abulfeda cuenta que una vieja preguntaba á Mahoma que había que hacer para ganar el paraíso, y que el profeta le contestó: «El paraíso no es para las viejas». Y habiéndose echado á llorar la vieja al oír esto, Mahoma añadió:

-Consolaos, si no hay viejas en el paraíso es porque rejuvenecen todas, todas al entrar allí.

-Alabados sean Dios y su profeta, exclamó la vieja marchándose (El Correo Español, 1896, 1) $)^{17}$.

Solo unos días después, el 2 de diciembre de 1896, idéntico texto se imprimía en la sección «algo de todo» del periódico El Áncora: diario católico-popular con censura eclesiástica, impreso en Palma de Mallorca $(1896,1)^{18}$. En esta ocasión, el cuentecillo fue claramente rescatado de las páginas del El Correo Español, de donde también se tomó el texto que le precede en el citado número del diario balear.

${ }^{14}$ Disponible en línea: http://hemerotecadigital.bne.es/issue.vm?id=0000190982\&page $=3 \&$ search $=$ abulfeda + mahoma\&lang=es (consultada 16-2-2017).

15 Precisamente se debe a la prensa decimonónica su contribución al desarrollo independiente del cuento en tanto género.

${ }_{16}$ Texto accesible en formato digital: https://texashistory.unt.edu/ark:/67531/metapth193068/ $\mathrm{m} 1 / 2 /$ (consultada 16-2-2017).

17 Accesible en línea: http://hemerotecadigital.bne.es/issue.vm?id=0029797237\&page=1 \&search=abulfeda+mahoma\&lang=es (consultada 16-2-2017).

${ }_{18}$ Disponible en línea: http://prensahistorica.mcu.es/es/publicaciones/numeros_por_mes. cmd?idPublicacion=3055 (consultada 16-2-2017). 


\section{UN RELATO DE TEMÁTICA Y ORIGEN ÁRABE}

La presencia del cuentecillo en la Península Ibérica no comienza, sin embargo, en el s. XIX. Ya lo relataba a finales del s. XIV un literato granadino llamado Ibn 'Asim (m. 1426) en una obra que guarda bastantes semejanzas con las de Rafael Boira y Roberto Robert. Titulada Hada'iq al-azahir, su principal finalidad era divertir. Para ello, su autor se sirvió de todo tipo de anécdotas, chistes, respuestas ingeniosas e historias más extensas, junto con una colección de refranes y otra muy breve de sentencias, esta última de marcado carácter sapiencial y que se aleja de la tónica general del conjunto. Ofrezco la traducción del texto que recogía el granadino, cuya línea argumental es prácticamente la misma que el de aquel que recuperarían los literatos españoles del XIX. El de Ibn 'Asim -menos elaborado- dice así:

El Profeta, ¡Dios le bendiga y salve!, solía bromear y no decía sino la verdad. Acerca de eso son las palabras que [dirigió] a una de sus tías paternas: $-\ll i \mathrm{Al}$ Paraíso no entra ninguna vieja!». Y cuando ella se afligió por eso, le dijo: - «iDios las hará el día de la Resurrección jóvenes y vírgenes!» (Ibn 'Asim 1992, 140; trad. esp. López Bernal 2020, 165, n⿳0 384).

El texto árabe se compone en realidad de dos hadices. Los hadices son relatos que nos hablan de los dichos y del modo de proceder ante variadas situaciones del profeta Muhammad (Mahoma), considerado el modelo a seguir por todo buen musulmán. Fueron memorizados por sus Compañeros y transmitidos durante generaciones de forma oral hasta ser recogidos por escrito en diferentes colecciones a partir del s. $\mathrm{IX}^{19}$. El conjunto de los hadices conforma la Sunna o Costumbre, que es la segunda fuente en importancia de la ley y el derecho islámicos, por lo que muchas de estas narraciones experimentaron una amplísima difusión oral.

El relato transmitido en la obra de Ibn 'Asim da comienzo con un primer hadiz («El Profeta, ¡Dios le bendiga y salve!, solía bromear y no decía sino la verdad») muy extendido en los textos árabe-islámicos medievales para ejemplificar la inclinación de Mahoma a reír y bromear. Con ello se perseguía justificar la posición favorable a la risa de sus autores, en el marco del debate sostenido durante la Edad Media por los intelectuales árabe-islámicos en torno a esta cuestión y su mayor o menor peso frente a la seriedad en la vida de los musulmanes. La polémica llegó a convertirse prácticamente en un auténtico cliché en los prólogos de los libros del género literario del adab, a cuyas características responde la colección de Ibn 'Asim. El adab fue un género misceláneo en el que se mezcla la prosa (más abundante) con el verso, y que re-

19 La palabra «hadiz» procede de la raíz árabe hadatha («contar», «relatar») y tiene un marcado componente oral. Más detalles sobre el término en Robson 1975-2007, 24-30. 
curre a variadas formas narrativas breves para abordar todo tipo de temáticas desde un enfoque y con un fin enciclopédicos, que responden a su concepción instructiva. Las obras de $a d a b$ constituyen verdaderas enciclopedias y proporcionaron al individuo árabe-islámico cultivado el saber que se esperaba de él. Se perseguía ser didáctico, y para ello se alternó el contenido y el tono más grave con el más festivo ${ }^{20}$.

Como decía, era costumbre extendida entre quienes cultivaron el género incluir en sus libros una serie de relatos como el que estamos abordando, dispuestos de forma correlativa y protagonizados por Mahoma, sus Compañeros y otros personajes del islam considerados un ejemplo por su recta conducta moral (Ibn 'Abd Rabbihi 1983, VIII: 90-93; al-Ibshihi 1992, II: 311-312; al-Nuwayri 2004, IV: 3-9). Con ellos, que mostraban que Mahoma bromeaba y reía incluso con asuntos trascendentales como la muerte ${ }^{21}$, no se buscaba otra cosa que justificar la dedicación de estas obras (o de parte de sus capítulos) a la risa y a hacer reír. Así se explica el cuentecillo completo en el contexto general lo mismo de las demás obras de adab que mencionaré, que en los Hada'iq al-azahir de Ibn 'Asim, donde el humor es el factor dominante.

Me centraré ahora en el texto que acoge el cuentecillo transmitido a la literatura española, el segundo de los hadices apuntados. Su manifestación escrita más antigua se halla en la recopilación reunida en el s. IX por al-Tirmidhi (m. 892), cuya gran colección está considerada la cuarta en importancia en el derecho islámico (Juynboll 1975-2007, 587). La recopilación a la que me refiero -titulada al-Shama'il al-Muhammadiyya-, la dedicó en exclusiva a reunir los hadices que hablaban de las características de Mahoma, entre las que se contaba su modo de reír y su gusto por bromear. El hadiz que nos interesa es el último que ilustra esta segunda cualidad mencionada. Su texto -precedido de una cadena de transmisión de cuatro informantes (que aquí omitimos)- es el que sigue:

Una vieja llegó al Profeta, ¡Dios le bendiga y salve!, y dijo: -“¡Oh Enviado de Dios, ruega a Dios que me haga entrar en el Paraíso!”. Y él respondió: -“ $i O h$, madre de Fulano, en el Paraíso no entra ninguna vieja!". Dijo: Entonces ella se dio la vuelta llorando. Y él dijo: -"Informadle de que no entrará en él siendo vieja, ya que Dios el Altísimo dice: «Nosotros las hemos creado de manera especial y hecho vírgenes, afectuosas, de una misma edad» (al-Tirmidhi 1996, 105).

${ }^{20}$ Sobre las características de este género, cfr. Gabrieli 1975-2007, 180-181 (síntesis del estudio de referencia que llevó a cabo Carlo Alfonso Nallino) y Pellat 1976, 19-37.

${ }^{21}$ Muy conocido es también otro hadiz en el que Mahoma bromea con una mujer al preguntarle por la causa de que en los ojos de su marido haya blanco, lo que le hace creer a ella que ha muerto. Sobre sus versiones literarias árabes medievales cfr. Marzolph 1992, II: $122 \mathrm{n}^{\circ}$ 485. Añádase a las que se mencionan la contenida en Ibn 'Asim 1992, 140; trad. esp. López Bernal 2020, 166, $\mathrm{n}^{\circ} 385$. 
La historia que se cuenta guarda relación con los versículos 35-37 de la azora 56 del Corán, de nombre «El acontecimiento» $(1999,715)$, con los que aquella finaliza. En ellos se alude a las huríes que los creyentes musulmanes encontrarán en el Paraíso, «vírgenes, afectuosas, de una misma edad» ${ }^{22}$.

A lo largo de la Edad Media y dentro de las fronteras del mundo árabe-islámico, seguimos hallando nuestro cuentecillo en obras de distinta naturaleza, desde el mencionado s. IX hasta el s. XV. Se cita en tratados de derecho islámico, en comentarios del Corán, en obras históricas y -sobre todo- en la literatura de $a d a b$, donde aparece hasta en ocho obras (todas ellas orientales salvo la de Ibn 'Asim) y en diferentes versiones ${ }^{23}$.

El recorrido por sus versiones literarias nos lleva en primer lugar al s. X-XI. Lo encontramos de forma esquemática y acompañado de una breve explicación en el capítulo que al-Abi (m. 1030-1031) tituló «las chanzas de los personajes nobles, los hombres ilustres y los sabios» dentro de su enciclopédica Nathr al-durr. Su texto también comienza con el primer hadiz al que aludíamos en párrafos anteriores: «Y dijo, ¡la paz sea sobre él!: En el Paraíso no entra ninguna vieja. Quiere decir que se volverán jóvenes y luego entrarán en el Paraíso» (al-Abi 1997, I: 290). Otro hombre de letras llamado al-Ragib al-Isfahani (m. durante el s. XI) le daba cabida en una enciclopedia de adab a la que denominó Muhadarat al-udaba'. Como ocurría en la anterior, el hadiz convertido en anécdota aparece en un apartado titulado «algo de lo que ha sido transmitido sobre los relatos acerca de las bromas», a su vez dentro del capítulo que dedica a hablar «sobre los Ansar, la moral y las bromas» ${ }^{24}$. Su texto dice así:

Se cuenta que el Profeta, ¡Dios le bendiga y salve!, era uno de los hombres más bromistas. Una vieja de entre los Ansar le dijo: $-«$ OOh Enviado de Dios, ruega [a Dios] de mi parte [entrar] en el Paraíso!». Y le respondió, ¡Dios le bendiga y salve!: -«¡En el Paraíso no entra ninguna vieja!». Entonces la mujer se echó a llorar y el Profeta, ¡Dios le bendiga y salve!, se echó a reír y dijo: - «¿Es que no has escuchado la palabra de Dios el Altísimo?: «nosotros las hemos creado de manera especial y hecho vírgenes, afectuosas, de una misma edad» (al-Ragib al-Isfahani s. d., I: 282).

En el s. XII, su presencia se advierte en las obras de dos autores. La primera versión de dicha centuria nos ha sido transmitida en Rabi' al-abrar wa-

${ }^{22}$ Un estudio de estos personajes femeninos en la tradición musulmana es el de Casti1lo Castillo 1985-1986, 7-18.

${ }_{23}$ A las versiones recogidas por Basset (1924-1927, II: 192, nº 89) y Marzolph (1992, II: $32, \mathrm{n}^{\circ} 118$ ), añado las siguientes: al-Tirmidhi. Al-Shamail al-Muhammadiyya (s. IX, colección de hadices); Ibn Hamdun. Al-Tadhkira al-hamduniya (s. XII, literatura de adab); al-Zamarjshari. Al-Kashshaf (s. XII, comentario del Corán); Ibn Kathir. Al-Bidaya wa-l-nihaya (s. XIV, obra histórica) e Ibn 'Asim. Hada'iq al-azahir (siglos XIV-XV, literatura de $a d a b)$.

${ }^{24}$ Los Ansar fueron los seguidores medineses de Mahoma. 
nusus al-ajbar de al-Zamarjshari (m. 1144), una voluminosa obra de adab, en cuyo capítulo sobre «las facecias, las chanzas y los chistes» se cuenta:

Una vieja de los Ansar llegó al Enviado de Dios, ¡Dios le bendiga y salve!, y le dijo: -“¡Oh Enviado de Dios, ruega de mi parte [a Dios] el perdón!”. Y le contestó: -“¿Es que no has sabido que en el Paraíso no entran las viejas?”. Entonces ella gritó y el Enviado de Dios sonrió y dijo: - ¿Es que no has leído que «nosotros las hemos creado de manera especial y hecho vírgenes, afectuosas, de una misma edad» (al-Zamajshari 1992, V: 118).

El último testimonio literario del s. XII se lee en al-Tadhkira al-hamduniya, obra de características similares a las que se vienen citando. Se cuenta en el capítulo 48, en el que su autor, Ibn Hamdun (m. 1166-1167), reunió facecias y anécdotas. Su texto (1996, IX: 364, n. ${ }^{\circ}$ 715) es prácticamente igual al que traducíamos con anterioridad.

En las restantes versiones que nos ofrece la literatura árabe medieval se repiten los mismos motivos y personajes que acabamos de ver: una mujer anciana (de los Ansar o no) llega a Mahoma y le pide que le conceda el Paraíso, a lo cual él responde bromeando siempre con la misma frase. La mujer se aflige (llora o grita) y Mahoma ríe o sonríe, remitiéndola a la revelación. La anécdota nos la cuentan Ibn al-Yawzi (m. 1200) en su Kitab al-adhkiya' (1985, 140), al-Nuwayri (m. 1332) en Nihayat al-arab (2004, IV: 6) y -unas décadas después que Ibn 'Asim de Granada- el egipcio al-Ibshihi (m. d. 1446) en al-Mustatraf fi kulli fann mustazraf (1992, II: 311). Este último lo incluye en el capítulo 75 de su enciclopédica obra, centrado en el hecho de bromear y en la conveniencia o no de hacerlo.

Ibn al-Yawzi es el único que -haciendo gala de su condición de eminente jurista- recogió la cadena de transmisión del relato hasta llegar a él $(1985,140)$. Es muy corta y desemboca en 'A'isha ( $c a$. 614-678), tercera de las esposas de Mahoma y favorita, a quien se le hace una pregunta sobre el gusto por bromear de su esposo. En su respuesta, 'A'isha refiere la anécdota, que en este caso ha sido más reelaborada por el de Bagdad:

Nos informó Sa'id b. al-Musayyab que preguntaron a 'A'isha, ¡Dios se apiade de ella!: - ¿El Enviado de Dios, Dios le bendiga y salve, solía bromear?»- Sí -contestó: Había en mi casa una anciana y llegó el Enviado de Dios, ¡Dios le bendiga y salve! Entonces ella le dijo: - «iPide a Dios que me coloque entre las gentes del Paraíso!». Él respondió: -«iEn el Paraíso no entran las viejas!». Y oyó que lo llamaban y salió. Y entró estando ella llorando y preguntó: - ¿QQué le pasa?». Y dijeron: - «Que le has contado que en el Paraíso no entran las viejas!». Y él dijo: -«Dios las hará "vírgenes, afectuosas, de una misma edad"».

El repaso a la huella de este viejo hadiz en la tradición árabe-islámica escrita de la Edad Media finaliza con su narración en una obra histórica, una de las más célebres en su género, que debemos al destacado tradicionista e histo- 
riador sirio Ibn Kathir (m. 1373). Al-Bidaya wa-l-nihaya-que así se llama esta obra- comprende la historia del califato islámico y finaliza con una crónica de la historia de Damasco (Laoust 1955, 75-85). Contiene una biografía de Mahoma (ibíd., 75-77), una de cuyas fuentes es precisamente al-Tirmidhi, a quien mencionábamos en páginas anteriores por ser su colección la primera en la que figura el cuentecillo. Ibn Kathir decía expresamente haberlo tomado de al-Shamail de aquel, y lo contaba en un capítulo dedicado a la afición del Profeta por bromear (2010, VI: 75).

Como veremos, basta con seguir la estela dejada por el hadiz hasta alcanzar el final de nuestra época medieval (s. XV) para tratar de dar una explicación a su presencia en las obras de Rafael Boira y Roberto Robert. Por supuesto, intuimos que el hadiz habría tenido una prolongada vida oral. El único testimonio que conservamos de ella son las cadenas de transmisión que se reproducen en algunas de las obras mencionadas.

\section{SOBRE CÓMO ALCANZÓ EL CUENTECILlo LA LiTERATURA ESPAÑOLA DEL S. XIX}

Es el momento de explorar las posibles vías por las que el cuentecillo llegó hasta los literatos españoles. Según se ha expuesto, su amplia difusión en el mundo árabe a lo largo de la Edad Media se debe en buena medida al hecho de tratarse de un hadiz, ligado a la figura de Mahoma y que aborda una cuestión muy debatida durante el medievo en todas las sociedades como fue aquella en torno a la risa ${ }^{25}$. Pero, ¿cómo se explica su inclusión en las colecciones de Rafael Boira y Roberto Robert?

Hasta donde se ha podido investigar, no hay rastro de él en obras de la literatura española de los siglos dorados ni posteriores hasta llegar al s. XIX. Tampoco me parece probable que el cuentecillo hubiera circulado oralmente por la Península Ibérica desde finales del s. XIV que lo recogía en al-Andalus Ibn 'Asim y lo incluía en sus Hada'iq al-azahir, dando el paso de la tradición árabe a la española, y que hubiera sido rescatado por escrito por ambos autores (o al menos por Boira, primero en hacerse eco de él). Esta trayectoria me parece descartable, pese a la gran acogida que tuvieron los Hada'iq al-azahir del granadino y al papel fundamental que desempeñaron en la transmisión de cuentecillos hacia la España de los siglos XVI y XVII. Para dar respuesta a la cuestión que planteamos debemos volver al Abulfeda, que aparecía como transmisor del relato en sus versiones literarias españolas.

Abu l-Fida' Isma'il b. 'Ali (m. 1331) fue un reputado historiador y geógrafo sirio, miembro de la dinastía de los ayyubies, que vivió entre los siglos XIII

${ }^{25}$ La bibliografía en torno a la risa en la Edad Media cristiana es bastante amplia. Cito los estudios básicos de Le Goff 1989; Horowitz y Menache 1994 y Verdon 2001. Por lo que respecta a las sociedades árabe-islámicas, cfr. Ammann 1993 y Pellat 1963. 
y XIV (Gibb 1975-2007, 122) ${ }^{26}$. Sobre todo a partir del s. XVIII, Abulfeda o Aboulfeda -como fue conocido en las lenguas occidentales- se convirtió en una de las fuentes de referencia en Europa para el estudio de la historia y de la geografía. El incipiente orientalismo comenzó entonces a interesarse masivamente por sus dos principales obras: un compendio de la historia de la humanidad que empieza en Adán y abarca hasta el año 1329 (=729 H.), titulado al-Mujtasar fi ajbar al-bashar y que fue conocido como la Historia de Abulfeda $^{27}$; y un tratado geográfico, Taqwim al-buldan. Ambos tuvieron una amplísima repercusión en el continente europeo durante los siglos XVII-XIX gracias a sus ediciones y traducciones parciales a diversas lenguas (Schnurrer 1811, $117-132)^{28}$.

Nuestro interés se centra ahora en la Historia de Abulfeda. En ella, el conjunto de capítulos en los que se habla de Mahoma -desde su nacimiento hasta su muerte-, de su familia, de las primeras batallas del islam o de los primeros en abrazarlo, se nos dibuja como una extensa biografía del Profeta. En principio, se podría pensar que el cuentecillo que buscamos podría hallarse en estos apartados de la obra de Abulfeda, cuya primera traducción a una lengua europea -mención aparte de su resumen y traducción al turco en el s. XVI- data del s. XVII y se debe a un cristiano de Oriente que residió en Italia y España llamado Marcos Dobelio ${ }^{29}$. Sin embargo, Dobelio tan solo volcó al español los apartados o fragmentos relacionados con la historia de al-Andalus, como se desprende del título con el que nos ha llegado: Suma que trata del tiempo cuando los mahometanos ganaron a África, y cómo después pasaron a España... vuelta de arábigo en romance ${ }^{30}$. Esto nos hace descartar que el hadiz referido a Mahoma se encontrase en ella y que -por tanto- hubiera podido ser conocido directamente en español por Rafael Boira y Roberto Robert.

${ }^{26}$ No debe confundirse con Ibn Kathir (citado en páginas anteriores), cuya alcurnia fue también Abu 1-Fida' y en cuya obra histórica se lee igualmente el cuentecillo, inserto -como en la Historia de Abulfeda, según se explicará- dentro de la sección sobre la semblanza de Mahoma y los acontecimientos que rodearon su vida y los inicios del islam.

${ }^{27}$ La obra fue resumida y ampliada posteriormente por otros autores árabes como Ibn al-Wardi (m. 1349), que le dio el título de Tatimmat al-Mujtasar fi ajbar al-bashar y la completó hasta el año 1349 (=749 H.).

${ }^{28}$ El Taqwim al-buldan, por ejemplo, fue traducido parcialmente al latín, al alemán y al francés (Gibb 1975-2007, 122).

${ }^{29}$ El carácter pionero de dicha traducción en Europa fue señalado por Rodríguez Mediano (2006, 261-262). Sobre su figura, ligada también a los célebres libros plúmbeos del Sacromonte de Granada cfr. García Arenal y Rodríguez Mediano 2010, 251-258 y Rodríguez Mediano 2006, 258-259.

${ }^{30}$ El texto manuscrito se halló entre los conocidos como «papeles» de Campomanes (Rodríguez Mediano 2006, 261-262). Parece, no obstante, que Dobelio pudo haber traducido algunas partes más de la Historia de Abulfeda que no nos han llegado (García Arenal y Rodríguez Mediano 2010, 267-269). 
La siguiente pista nos conduce a las numerosas obras que -a lo largo del s. XVIII y de la centuria siguiente- se imprimen en Occidente con el nombre de Vida de Mahoma (Chauvin 1892-1907, XI: 1-243; Kazimirski 1869, XXXIII-XXXIV). En concreto, fijamos nuestra atención en aquellas -igualmente cuantiosas- que dicen ser traducciones del texto sobre la biografía de Mahoma de Abulfeda y que aparecen en latín, francés e inglés (Chauvin 1892-1907, XI: 1-7 y 148). Todas ellas no son otra cosa que traducciones de los fragmentos relativos a la existencia vital de Mahoma que figuran en la Historia de Abulfeda.

La primera de estas traducciones fue obra del orientalista francés Jean Gagnier. Los franceses - por cierto- fueron los intelectuales más interesados en Abulfeda, como veremos en los párrafos que siguen. La traducción de Gagnier fue, sin duda, una de las de mayor éxito. Fue publicada en un primer momento en latín (1723) y casi una década más tarde en francés (1732). En una y otra consta el texto del cuentecillo, pero con una diferencia significativa en su presentación al público lector, que podría haber sido clave en la posterior circulación del relato por la tradición escrita europea.

Los fragmentos de la Historia de Abulfeda protagonizados por el Mahoma hombre de religión y de Estado y que configuran los primeros años de la historia del islam fueron volcados al latín por Jean Gagnier bajo el título $I s$ mael-Aboulfeda, de vita, et rebus gestis Mohammedis. La obra incorpora tanto la traducción en latín, como el texto árabe, pues es -al mismo tiempo- una traducción y una edición del manuscrito de la obra de Abulfeda conservado en la Biblioteca Bodleiana de Oxford. Para llegar hasta nuestro cuentecillo hay que buscar en su capítulo LXVI, titulado «De Natura, seu Indole ejus». Allí vemos que el relato de Mahoma y la anciana que quería entrar al Paraíso no se lee en el cuerpo del texto, sino en una nota del aparato crítico que se debe a Gagnier y que dice:

Familiaris erat. Neque seriis adeò rebus, et gravibus colloquiis in conversatione occupabatur Propheta, quin aliquando frontera exhilararet, et jocolis et argutè dictis delectaretus; ut hoc exemplo comprobatur in Traditionibus: [texto árabe del relato] Nonnunquam jocabatur; sed semper veritatem loquebatur: Venit ad eum quedam Muliercula dicens: O Apostole Dei, Deum roga, ut me in Paradisum introducat. Respondit: O Mater Talis, nulla Vetula in Paradisum ingressura est. Tum illa obortis lachrymis tergum vertit. Scilicet volebat dicere Propheta, cui Pax, illam adbuc Vetulam existentem in Paradisum non esse introituram, (antea enim debebat juvenescere), juxta illud Dei excelsi verbum, Al-Coran. Sur. 56. v. 37. «Nos certè creavimus illas (vetulas) creaturas-novas, et reddidimus eas virgines, conjugibus suis dilectas, illisque coetaneas» (Gagnier 1723, 145).

El propio Gagnier escribía que había tomado el hadiz de la Tradición o Sunna y -según parecen indicar algunas palabras o expresiones que he señalado en cursiva-, todo apunta a que efectivamente siguió el texto registrado por escrito en la colección de al-Tirmidhi, traducido en páginas anteriores. En 
principio, leyendo a Gagnier se entiende que el relato no pertenece al texto transmitido por Abulfeda. La confirmación se produce al cotejar el fragmento correspondiente en una edición moderna de al-Mujtasar o Historia del autor sirio (Abulfeda 1997, I: 215-216).

Una situación bien distinta es la que encontramos en la traducción que Jean Gagnier hizo al francés de la biografía de Mahoma y que se publicó con el título de La vie de Mahomet; Traduite et Compilée de l'Alcoran, des Traditions Authentiques de la Sonna, et des meilleures auteurs arabes. Es evidente que ya no se trata de una traducción del texto de Abulfeda exclusivamente. A él se han incorporado otros materiales, que Gagnier ha leído en otros autores, en colecciones de hadices e incluso en el Corán (recordemos que era profesor de lenguas orientales) ${ }^{31}$. El cuentecillo de Mahoma y la mujer anciana figura en el capítulo II del libro VII, titulado el primero «Du naturel du Prophète: de son esprit et de ses mœurs». Ya no aparece en nota, sino al hilo del texto, aunque Gagnier reproducía las mismas palabras que escribía en el aparato crítico de su traducción latina de Abulfeda:

Il n'étoit pas tellement occupé de discours graves et sérieux, qu'il ne déridât quelquefois son front, et ne mêlât dans la conversation des paroles enjouées et dites avec esprit: En voici un exemple tiré des Traditions: «Il railloit quelquefois, dit-on, mais il disoit toujours la vérité. Un jour une femmelette dévote se présenta à lui le suppliant de demander à Dieu pour elle, qu'il l'introduisit dans le $\mathrm{Pa}$ radis. Il lui répondit: Ô! la bonne Mère, aucune vieille n'entrera dans le Paradis. Surquoi cette bonne femme se mit à pleurer. Mais il la rapella; et pour la consoler, il lui expliqua l'équivoque, et lui fit entendre, que les vieilles femmes, avant que d'entrer en Paradis, seront rajeunies, selon ces paroles de l'Alcoran: «Certainement nous les ferons des créatures nouvelles (savoir les vieilles femmes), nous les rendrons vierges, aimables à leurs époux, de même âge qu'eux». Et ainsi il la congédia agréablement» (Gagnier 1732, II: 319).

También ligado a Abulfeda, este viejo hadiz se lee en otra obra del s. XVIII, el Dictionnaire philosophique de Voltaire, concebido como una enciclopedia ilustrada y que fue ampliado en sus sucesivas ediciones desde la prínceps, aparecida en 1764:

Abulfeda rapporte qu'une vieille l'importunant un jour, en lui demandant ce qu'il fallait faire pour aller en paradis: «M'amie, lui dit-il, le paradis n'est pas pour les vieilles». La bonne femme se mit à pleurer, et le prophète, pour la consoler, lui dit: «Il n’y aura point de vieilles, parce qu'elles rajeuniront». Cette doctrine consolante est confirmée dans le cinquante-quatrième chapitre du Koran (Voltaire $1878,105)$.

31 Obsérvese, en la figura de Gagnier y otros autores mencionados en adelante, el desarrollo paralelo del primer orientalismo y del también incipiente arabismo europeo científico, que convivió con otro puramente romántico y exótico. 
El movimiento orientalista francés continuó dando cuantiosos frutos en el s. XIX que miraban hacia el mundo árabe-islámico. Tras Jean Gagnier y siguiendo su texto, Joseph-Toussaint Reinaud retomaba el cuentecillo en su Description des monuments arabes, persans et turcs, du cabinet du duc de Blacas, impresa en 1828. Reinaud citaba el relato precisamente cuando se disponía a hablar del carácter afable y del gusto por bromear de Mahoma (1828, I: 272) y remitía a la traducción de Gagnier. No mencionaba a Abulfeda, pero el texto de Gagnier es una traducción de su biografía de Mahoma, con lo que quien leyera el libro de Reinaud bien podía entender que la historia la contaba el historiador árabe.

La cadena de equívocos pudo prolongarse con las páginas de una historia universal publicada en francés en el año 1844 bajo el título Le monde. Histoire de tous les peuples. Depuis les temps les plus reculés jusqu'à nos jours. Se trata de una serie confeccionada por varios autores en la que también había un hueco para tratar sobre Arabia. A lo largo de la sección que se le dedica, el principal referente es Abulfeda y los Annales Moslemici, traducción de su Historia llevada a cabo por Jacob Reiske en cinco volúmenes en el año 1754, que también contiene la biografía de Mahoma. Nuestro cuentecillo, en cambio, lo toman de Reinaud, al que se cita explícitamente (Saint-Prosper et al. 1844, $\mathrm{X}: 260$ ).

Muy del gusto de la época y del afán por conocer otros mundos y culturas más allá de la propia, la colección fue traducida muy pronto al español, al menos algunos de sus volúmenes, que fueron publicados en la imprenta de A. Brusi de Barcelona en los años 40 de la centuria decimonónica. La traducción era de Juan Cortada, historiador y periodista, que escribió bajo el pseudónimo de Aben-Abulema (Ghanime 2012) (2) $^{32}$ Tengo noticias de la traducción de los volúmenes correspondientes a la Historia de América; Alemania, Prusia y Austria; España; Francia; Grecia e Italia; Inglaterra; Portugal y Tierra Santa (Biblioteca Nacional de España, Catálogo y Biblioteca Digital Hispánica) ${ }^{33}$. Desconozco qué ocurrió con los restantes. De haber sido traducido al español el correspondiente a Arabia, habría que tener en cuenta la posibilidad de que Rafael Boira y Roberto Robert hubieran podido acceder al cuentecillo a través de esta obra.

Sin conexión alguna con Abulfeda, nuestro relato aparece también en una obra que vio la luz en la Francia de inicios del s. XVIII, admirada por los cuentos orientales y exóticos tras la aparición del primer volumen de la traducción

\footnotetext{
32 Accesible en: http://www.upf.edu/obraperiodistica/es/anuari-2012/joan-cortada-abenabulema.htm (consultada 15/3/2017).

${ }^{33} \mathrm{http}: / /$ catalogo.bne.es/uhtbin/webcat (consultado 25/2/2017, búsqueda realizada: «el mundo historia de todos los pueblos»); http://bdh.bne.es/bnesearch/Search.do?numfields=1\&field $1=$ autor \& field $1 \mathrm{val}=\% 22 \mathrm{Cortada} \% 2 \mathrm{c}+\mathrm{Juan} \% 22 \&$ field $1 \mathrm{Op}=\mathrm{AND} \&$ exact $=$ on\&advance$\mathrm{d}=$ true \&language $=$ esEn (consultada 25/2/2017).
} 
de las Mil y una noches debida a Antoine Galland (1704), en la que se inspiraron otros libros aparecidos desde entonces. En efecto, Les mille et un jours: contes persans, suivis de plusieurs autres recueils de contes traduits des langues orientales (1710-1712) de François Pétis de la Croix se inscriben dentro de la tradición de las Mil y una noches y del gusto e interés hacia los cuentos persas y árabes, y nacieron alentados por el éxito de los de Galland (Dufrenoy 19461947, I: 34; Hahn 2002, 48-50) ${ }^{34}$. La edición que manejamos data de 1840 (la obra fue reimpresa varias veces a lo largo del s. XIX) e incluye notas y noticias históricas a cargo de Auguste Louis Armand Loiseleur-Deslongchamps (m. 1840), añadidas - por tanto- con posterioridad a su edición prínceps. En una de ellas, y a propósito de si Mahoma dio entrada o no a las mujeres en el Paraíso, se ofrece la traducción de nuestro hadiz, que Loiseleur-Deslongchamps tomó de la publicada - a partir de un relato en persa- por otro orientalista, Jean-Baptiste-André Grangeret de Lagrange (m. 1859), en el Journal Asiatique de febrero de 1835 (Grangeret de Lagrange 1835, 195-196):

Le meilleur et le plus grand des hommes (que Dieu répande sur lui ses bénédictions les plus abondantes!) plaisantait volontiers: Mais de temps en temps, et lorsqu'il laissait échapper la plaisanterie dans ses paroles saintes, il ne disait jamais que la vérité, et c'était toujours d'une manière adroite et indirecte. On rapporte qu'il dit une fois à une vieille femme: Au jour de la résurrection, aucune vieille femme n'entrera dans le paradis. La vieille, toute troublée, s'écria avec douleur: O prophète de Dieu! Quelles fautes, nous pauvres vieilles femmes, avonsnous commises pour que nous soyons privées du bonheur d'entrer dans le paradis? L'élu de Dieu (que les bénédictions célestes reposent sur lui!) fit un sourire, puis, écartant le voile de rubis qui couvrait les perles de ses dents, il dit: Le Créateur (qu'il soit glorifié!) rajeunira toutes les vieilles femmes et les introduira dans le paradis (Pétis de la Croix 1840, 325).

Se trata de un relato más reelaborado y al que se añaden algunos detalles que -mención aparte de su contenido argumental, que es en todas las versiones reproducidas hasta el momento más o menos coincidente- comparte con el relato árabe que citábamos y con las versiones españolas decimonónicas todos sus elementos característicos.

\section{CONCLUSIONES}

Una vez seguidas las pistas del cuentecillo de origen árabe hasta alcanzar la Europa del s. XIX, parece claro que la mayoría de sus versiones europeas -recogidas ya sea en obras literarias, en relatos de la vida de Mahoma o en

${ }^{34} \mathrm{Si}$ se desea profundizar en las fuentes y originalidad de François Pétis de la Croix cfr. Hahn 2002, 50-53. 
enciclopedias históricas universales- se hallan directa o indirectamente vinculadas a la biografía del Profeta del islam incluida por Abulfeda en su Historia de título al-Mujtasar fi ajbar al-bashar. Este vínculo -en cambio- no es real, dado que -como se ha señalado- en su texto árabe no hay rastro del relato. Tampoco en la tradición árabe medieval se han encontrado referencias que ya lo ligasen a Abulfeda.

Es evidente que el cuentecillo no lo transmitió el historiador árabe en su obra. La confusión y atribución a él se produce -según mi hipótesis- a partir de que el orientalista francés Jean Gagnier lo incorporara a la traducción que realizó de la vida de Mahoma relatada por Abulfeda. Pienso que autores posteriores a Gagnier podrían haber interpretado que se debía a aquel y así lo expresaron por escrito, atribuyéndole su transmisión.

En cuanto a su presencia en la literatura española decimonónica, no sabemos cómo conocieron Rafael Boira y Roberto Robert el cuentecillo. Lo más probable es que lo hubieran leído en una obra de algún autor francés, bien de entre las señaladas, o bien en alguna colección de cuentos similar a las suyas, en la que no lo he alcanzado a identificar. De hecho, ambos declaran en los títulos que dieron a sus obras haber recurrido también a libros de cuentos y autores «extranjeros».

Lo que sí estamos en condiciones de afirmar es que -aunque conocido desde al menos el siglo anterior- fue durante el s. XIX cuando el relato adquirió una considerable difusión escrita en Europa. También en España, donde se ha podido documentar, además, en la prensa decimonónica. Las variaciones entre sus versiones españolas son -como se ha comprobado- muy leves, pero nos sitúan ante un cuentecillo tradicional dentro de la tradición escrita de aquel siglo. Detrás de su éxito entre los literatos españoles y europeos se halla el gusto de la época por los temas orientales, pese a que su llegada a España se produce precisamente cuando el movimiento cultural e intelectual del orientalismo ha alcanzado prácticamente su cénit.

Pese a la importante transmisión oral que debió conocer en el mundo árabe-islámico, su difusión por Europa se produjo por la vía erudita y escrita, a partir de que el hadiz fuera retomado en el marco de las traducciones y el interés hacia la vida de Mahoma, en alza desde finales del s. XVII. Una vez en la tradición europea escrita, el relato se transmitió ligado a dos cuestiones fundamentales: el carácter bromista de Mahoma y la supuesta exclusión del islam hacia las ancianas para entrar en el Paraíso. El entusiasmo orientalista -ya sea romántico o científico- que se extiende entonces por el continente europeo permite la introducción de estos temas en la literatura española del XIX, aunque en las colecciones en las que se inserta no se atiende a ellos y solo se contempla el relato como un chistecillo más que persigue dibujar una sonrisa en el lector. Un lector que en los Siglos de Oro reía con cuentecillos de origen árabe protagonizados por personajes populares y que en el s. XIX lo hace también con otros que tienen como protagonistas a personajes de la tradición árabe-islámica, con 
y de los que se ríe, pues -pese a la admiración y atracción que despiertan su mundo y su cultura- el sentimiento antisemita convive con ellas y aflora en muchos relatos, lo mismo en la literatura que en la prensa ${ }^{35}$.

Finalmente, el texto estudiado es un ejemplo de cómo un relato de la tradición religiosa llegó a alcanzar la categoría de cuentecillo. Como se pone de manifiesto tras su rastreo en la tradición árabe, esta metamorfosis ya tuvo lugar en la propia sociedad de origen donde, desde el s. IX, se difundió principalmente en libros de $a d a b$ y se le dio el mismo tratamiento literario que a materiales como las chanzas o las facecias, entre las que -de hecho- se incluyó. Sus autores pretendían así hacer un alegato a favor de la presencia de la risa en las vidas de los musulmanes. El proceso fue similar en Europa, donde entró como tradición o hadiz para acabar reproduciéndose en toda clase de obras de corte orientalista, así como en colecciones de cuentos como las de Rafael Boira y Roberto Robert.

\section{BIBLIOGRAFÍA CITADA}

Al-Abi, Abu Sa‘d Mansur. 1997. Nath al-durr. Editado por Mazhar al-Hayyi. 4 vols. Damasco: Manshurat Wizarat al-Thaqafa fi 1-Yumhuriyya al-'Arabiyya al-Suriyya.

Abulfeda=Abu 1-Fida'. 1997. Tarij Abi l-Fida' (=al-Mujtasar fi ajbar al-bashar). Editado por Mahmud Dayyub. 2 vols. Beirut: Dar al-Kutub al-'Ilmiyya.

Agúndez García, José Luis. 2004. «Tradición oral y literatura (II). Cuentecillos de Santa Cruz en Rafael Boira». Revista de Folklore 288: 194-207.

Agúndez García, José Luis. 2005. «Tradición oral y literatura (III). Cuentecillos de Roberto Robert en Rafael Boira». Revista de Folklore 290: 62-72.

Agúndez García, José Luis. 2006a. «Tradición oral y literatura (IV). Cuentecillos de Francisco Asensio en Rafael Boira» Revista de Folklore 302: 57-72.

Agúndez García, José Luis. 2006b. «Tradición oral y literatura (VI). Cuentecillos de Timoneda, Aragonés y Medrano en Rafael Boira». Revista de Folklore 310: 111-118.

Agúndez García, José Luis. 2006c. «Tradición oral y literatura (VII). Cuentecillos de Fernández de Velasco en Rafael Boira». Revista de Folklore 311: 147-154.

Ammann, Ludwig. 1993. Vorbild und Vernunft: Die Regelung von Lachen und Scherzen im mittelalterlichen Islam. Hildesheim: Olms.

Amores, Montserrat. 1997. Catálogo de cuentos folclóricos reelaborados por escritores del siglo XIX. Madrid: CSIC.

Amores, Montserrat. 2001a. «Cuentos de vieja, de Juan de Ariza. La primera colección de cuentos folclóricos españoles». Scriptura 16: 25-46.

Amores, Montserrat. 2001b. Fernán Caballero y el cuento folklórico. El Puerto de Santa María: Ayuntamiento de El Puerto de Santa María.

${ }^{35}$ En líneas generales, como señalaba Rehrmann (2007, 209), la literatura romántica asistió a una dicotomía entre moros buenos y judíos malos. No obstante, a lo largo de todo el s. XIX es posible advertir igualmente en la literatura española un acusado rechazo hacia los elementos árabe-islámicos. Sobre la representación de moros y judíos en la literatura española decimonónica consúltese el trabajo del mismo autor (2007, 207-222). 
Baquero Goyanes, Mariano. 1949. El cuento español en el siglo XIX. Madrid: CSIC.

Basset, René. 1924-1927. Mille et un contes, récits et légendes arabes. 3 tomos. Paris: Maisonneuve.

Boira, Rafael. 1862. El libro de los cuentos, colección completa de anécdotas, cuentos, gracias, chistes, chascarrillos, dichos agudos, réplicas ingeniosas, pensamientos profundos, sentencias, máximas, sales cómicas, retruécanos, equívocos, símiles, adivinanzas, bolas, sandeces y exageraciones. Almacén de gracias y chistes. Obra capaz de hacer reir a una estatua de piedra, escrita al alcance de todas las inteligencias y dispuesta para satisfacer todos los gustos. Recapitulación de todas las florestas, de todos los libros de cuentos españoles, y de una gran parte de los extranjeros. 3 tomos. $2^{\mathrm{a}}$. ed. Madrid: Imprenta de Miguel Arcas y Sánchez.

Castillo Castillo, Concepción. 1985-1986. «Las huríes en la tradición musulmana». Miscelánea de Estudios Árabes y Hebraicos 34-35 (1): 7-18.

Chauvin, Victor. 1892-1907. Bibliographie des ouvrages arabes ou relatifs aux Arabes publiés dans l'Europe chrétienne de 1810 à 1885. 12 tomos. Liège - Leipzig: Vaillant - O. Harrassowitz.

Chevalier, Maxime. 1978a. Folklore y literatura: el cuento oral en el Siglo de Oro. Barcelona: Crítica.

Chevalier, Maxime. 1978b. «Inventario de los cuentos folklóricos recogidos por Fernán Caballero». Revista de dialectología y tradiciones populares 34: 49-66.

Chevalier, Maxime. 1982. "Cuento folklórico y literaturas del siglo XIX». En Actas del VII Congreso de la Asociación Internacional de Hispanistas I, 325-333. Roma: Bulzoni.

Chevalier, Maxime. 1984. «La trayectoria del cuento folklórico en las letras españolas de la Edad Media al siglo XIX». Cuadernos para investigación de la literatura hispánica 6 : 195-208.

Dufrenoy, Marie-Louise. 1946-1947. L'Orient romanesque en France. Montreal: Beauchemin.

El Corán. 1999. Trad. Julio Cortés. Barcelona: Herder.

Fradejas Lebrero, José y José Luis Agúndez García. 2006. «Tradición oral y literatura. (V). Cuentecillos de Fernán Caballero en Rafael Boira». Revista de Folklore 304: 120-131.

Gabrieli, Francesco. 1975-2007. «Adab». En L'Encyclopédie de l'Islam, ed. Hamilton Alexander Rosskeen Gibb, Johannes Hendrik Kramers, Évariste Lévi-Provençal y Joseph Schacht, 180-181, 2. ${ }^{\mathrm{a}}$ ed. Vol. 1. Leiden: E. J. Brill.

García Arenal, Mercedes y Fernando Rodríguez Mediano. 2010. Un Oriente español: los moriscos y el Sacromonte en tiempos de Contrarreforma. Madrid: Marcial Pons.

Gagnier, Jean. 1723. Ismael-Abu'l-Feda, de vita, et rebus gestis Mohammedis, Moslemicae Religionis Auctoris, et Imperii Saracenici Fundatoris. Oxonia: Theatro Sheldoniano.

Gagnier, Jean. 1732. La vie de Mahomet; Traduite et Compilée de l'Alcoran, des Traditions Authentiques de la Sonna, et des meilleures auteurs arabes. 2 tomos. Amsterdam: Wetstein \& Smith.

Ghanime, Albert. 2012. «Aben-Abulema (Joan Cortada) y el Diario de Barcelona (18381841)». Obra periodística 3. http://www.upf.edu/obraperiodistica/es/anuari-2012/ joan-cortadaaben-abulema.html

Gibb, Hamilton Alexander Rosskeen. 1975-2007. «Abu 1-Fida'». En L'Encyclopédie de l'Islam, ed. Hamilton Alexander Rosskeen Gibb, Johannes Hendrik Kramers, Évariste Lévi-Provençal y Joseph Schacht, 122, 2.. ed. Vol. 1. Leiden: E. J. Brill.

Grangeret de Lagrange, Jean-Baptiste-André. Febrero 1835. «Analectes». Journal Asiatique 86: 195-197.

Gutiérrez Díaz-Bernardo, Esteban. 2003. El cuento español del siglo XIX. Madrid: Ediciones del Laberinto. 
Hahn, Franz. 2002. François Pétis de La Croix et ses Milles et Un Jours. Amsterdam - New York: Rodopi.

Horowitz, Jeannine y Menache, Sophia. 1994. L'humour en chaire: le rire dans l'église medievale. Genève: Labor et Fides.

Ibn 'Abd Rabbihi. 1983. Al-'Iqd al-farid. Editado por Mufid Muhammad Qumayha y 'Abd al-Mayid al-Tarhini. 9 vols. Beirut: Dar al-Kutub al-'Ilmiyya.

Ibn 'Asim, Abu Bakr. 1992. Hada'iq al-azahir. Editado por Abu Hammam 'Abd al-Latif 'Abd al-Halim. Beirut - Sidón: al-Maktaba al-'Asriyya; traducida al español por Desirée López Bernal. 2020. El libro de los huertos en flor (Hadā'iq al-azāhir). Cuentos, refranes y anécdotas de la Granada nazarí. Granada: Editorial Universidad de Granada.

Ibn Hamdun, Muhammad b. al-Hasan. 1996. Al-Tadhkira al-hamduniyya. Editado por Ihsan 'Abbas y Bakr 'Abbas. 10 vols. Beirut: Dar Sadir.

Ibn Kathir, Isma'il b. 'Umar. 2010. Al-Bidaya wa-l-nihaya. Editado por Muhiyy al-Din Mistu. 20 vols. Damasco - Beirut: Dar Ibn Kathir.

Ibn al-Yawzi, Abu 1-Faray 'Abd al-Rahman. 1985. Kitab al-adhkiya'. Beirut: Dar al-Kutub al-'Ilmiyya.

Al-Ibshihi, Abu 1-Fath Muhammad. 1992. Al-Mustatraf fi kulli fann mustazraf. 2 vols. Beirut: Manshurat Dar Maktabat al-Haya.

Juynboll, G. H. A. 1975-2007. «Al-Tirmidhī». En L'Encyclopédie de l'Islam, ed. Hamilton Alexander Rosskeen Gibb, Johannes Hendrik Kramers, Évariste Lévi-Provençal y Joseph Schacht, 587, 2. ${ }^{\mathrm{a}}$ ed. Vol. 10. Leiden: E. J. Brill.

Kazimirski, Albin de Biberstein. 1869. Le Koran. Traduction nouvelle faite sur le texte arabe. Paris: Charpentier.

Laoust, Henri. 1955. «Ibn Kathir historien». Arabica 2: 42-88.

Le Goff, Jacques. 1989. «Rire au Moyen Âge». Cahiers du Centre de Recherches Historiques 3. http://doi.org/10.4000/ccrh. 2918

Litvak, Lily. 1985. El jardín de Alá. Temas del exotismo musulmán en España (1880-1913). Granada: Editorial Don Quijote.

Marzolph, Ulrich. 1992. Arabia Ridens: Die Humoristische Kurzprosa der Frühen Adab-Literatur im Internationalen Traditionsgeflecht. 2 vols. Frankfurt am Main: V. Klostermann.

Al-Nuwayri, Ahmad. 2004. Nihayat al-arab fi funun al-adab. Editado por Mufid Qumayha et al. 33 vols. Beirut: Dar al-Kutub al-'Ilmiyya.

Palomo, María del Pilar. ed. 1997. Movimientos literarios y periodismo en España. Madrid: Editorial Síntesis.

Pellat, Charles. 1963. «Seriousness and Humour in Early Islam». Islamic Studies 2: 353-362.

Pellat, Charles. 1976. «Variations sur le thème de l'adab». En Études sur l'histoire socio-culturelle de l'Islam (VIIe-XVe siècle), Charles Pellat, 19-37. Londres: Variorum Reprint.

Pérez Zaragoza Godínez, Agustín. 1821. El remedio de la melancolía: la Floresta del año de 1821, o colección de recreaciones jocosas e instructivas. Obra nueva que contiene lo que se ha escrito e inventado mas agradable por autores modernos hasta el año de 1821 i en clase de anecdotas, apotegmas, dichos notables i agudezas, aventuras, sentencias, sucesos raros y desconocidos, egemplos memorables, chanzas ligeras, singulares rasgos históricos, juegos de sutileza y baraja, problemas de aritmetica, geometria y fisica, los mas fáciles, agradables é interesantes. Traducidas y recopiladas de diferentes autores franceses y otros. 4 tomos. Madrid: Imprenta de Álvarez.

Pétis de La Croix, François. 1840. Les mille et un jours: contes persans, suivis de plusieurs autres recueils de contes traduits des langues orientales. Paris: Auguste Desrez. Primera edición: $1710-1712$. 
Al-Ragib al-Isfahani, al-Husayn b. Muhammad. s. d. Muhadarat al-udaba'wa-muhawarat al-shu'ara' wa-l-bulaga'. 4 vols. Beirut: Manshurat Maktabat al-Haya.

Rehrmann, Norbert. 2007. «El síndrome de Cenicienta: moros y judíos en la literatura española del siglo XIX y XX». En El antisemitismo en España, coords. Gonzalo Álvarez Chillida y Ricardo Izquiero Benito, 207-236. Cuenca: Ediciones de la Universidad de Castilla-La Mancha.

Reinaud, Joseph-Toussaint. 1828. Description des monuments arabes, persans et turcs, $d u$ cabinet $d u$ duc de Blacas. 2 vols. Paris: Imprimerie Royale.

Robert, Roberto. 1866. El mundo riendo. Gracias y desgracias chistes y sandeces, epigramas y necedades, cuentos é historias, redundancias y laconismos, problemas y claridades, anuncios, apotegmas, despropósitos, malicias y otras cosas que no son nada de lo dicho. Colección enorme, selecta, novísima en prosa y verso sacada de autores antiguos y modernos, nacionales y extranjeros, clérigos y seglares, famosos y oscuros. 2. ${ }^{\mathrm{a}} \mathrm{ed}$. Barcelona: Librería Española de I. López Bernagosi.

Robson, J. 1975-2007. «Hadīth». En L'Encyclopédie de l'Islam, ed. Hamilton Alexander Rosskeen Gibb, Johannes Hendrik Kramers, Évariste Lévi-Provençal y Joseph Schacht, 24-30, 2. a ed. Vol. 3. Leiden: E. J. Brill.

Rodríguez Mediano, Fernando. 2006. «Fragmentos de orientalismo español del s. XVII». Hispania 66 (222): 243-275. https://doi.org/10.3989/hispania.2006.v66.i222.8

Saint-Prosper, Antoine-Jean et al. 1844. Le monde. Histoire de tous les peuples. Depuis les temps les plus reculés jusqu'à nos jours. 10 tomos. Paris: Béthune et Plon. 1. ${ }^{\mathrm{a}}$ ed. Paris: P. Duménil, 1838-1840.

Schnurrer, Christian Friedrich. 1811. Bibliotheca Arabica. Auctam nunc atque integram. Halae ad Salam: Typis et sumtu I.C. Hendelii.

Al-Tirmidhi, Muhammad b. 'Isà. 1996. Al-Shama'il al-Muhammadiyya wa-l-jasa'il al-mustafawiyya. Editado por Muhammad 'Abd al-'Aziz al-Jaladi. Beirut: Dar al-Kutub al-'Ilmiyya.

Valera, Juan. 1896. Cuentos y chascarrillos andaluces tomados de la boca del vulgo. Madrid: Librería de Fernando Fé.

Verdon, Jean. 2001. Rire au Moyen Âge. Paris: Perrin.

Voltaire. 1878. Euvres complètes de Voltaire 17. Dictionnaire philosophique I. Paris: Garnier Frères. 1. ${ }^{\mathrm{a}}$ ed. Genève: Gabriel Grasset, 1764.

Al-Zamajshari, Abu 1-Qasim Mahmud. 1992. Rabi“ al-abrar wa-nusus al-ajbar. Editado por 'Abd al-Amir Muhannà. 5 vols. Beirut: Manshurat Mu'assasat al-A'lami li 1-Matbu'at.

Fecha de recepción: 12 de mayo de 2017.

Fecha de aceptación: 23 de agosto de 2017. 